\title{
Anti-Biofilm Performance of Three Natural Products against Initial Bacterial Attachment
}

\author{
Maria Salta ${ }^{1}{ }^{*}$, Julian A. Wharton ${ }^{1}$, Simon P. Dennington ${ }^{1}$, Paul Stoodley ${ }^{1}$ and \\ Keith R. Stokes ${ }^{1,2}$
}

1 National Centre for Advanced Tribology at Southampton (nCATS), Engineering Sciences, University of Southampton, Highfield, Southampton SO17 1BJ, UK;

E-Mails: j.a.wharton@soton.ac.uk (J.A.W.); s.p.dennington@soton.ac.uk (S.P.D.); p.stoodley@soton.ac.uk (P.S.); krstokes@dstl.gov.uk (K.R.S.)

2 Physical Sciences Department, the Defence Science and Technology Laboratory, Porton Down, Salisbury, Wiltshire SP4 0JQ, UK

* Author to whom correspondence should be addressed; E-Mail: m.salta@soton.ac.uk; Tel.: +44-0-2380-593761; Fax: +44-0-2380-5930161.

Received: 18 September 2013; in revised form: 13 October 2013 / Accepted: 15 October 2013 / Published: 4 November 2013

\begin{abstract}
Marine bacteria contribute significantly towards the fouling consortium, both directly (modern foul release coatings fail to prevent "slime" attachment) and indirectly (biofilms often excrete chemical cues that attract macrofouling settlement). This study assessed the natural product anti-biofilm performance of an extract of the seaweed, Chondrus crispus, and two isolated compounds from terrestrial sources, (+)-usnic acid and juglone, against two marine biofilm forming bacteria, Cobetia marina and Marinobacter hydrocarbonoclasticus. Bioassays were developed using quantitative imaging and fluorescent labelling to test the natural products over a range of concentrations against initial bacterial attachment. All natural products affected bacterial attachment; however, juglone demonstrated the best anti-biofilm performance against both bacterial species at a concentration range between 5-20 ppm. In addition, for the first time, a dose-dependent inhibition (hormetic) response was observed for natural products against marine biofilm forming bacteria.
\end{abstract}

Keywords: marine bacteria; natural products; anti-biofilm; bacterial attachment 


\section{Introduction}

The underwater hull of a ship is exposed not only to the corrosive seawater environment, but also to the constant accumulation of biofouling. Biofouling, or marine growth, includes any attaching organisms, such as biofilms (mainly bacteria and diatoms), tubeworms, mussels, barnacles and algae.

Overall, biofouling is a major concern for submersed manmade structures, while, especially, vessel performance can be severely affected in terms of speed, hydrodynamic efficiency, fuel consumption and weight. Marine biofilms, which are mainly comprised of bacteria and diatoms embedded in an extracellular matrix [1], constitute a major component of the overall biofouling and may lead to a $14 \%$ increase in ship fuel costs, while an $8 \%-29 \%$ penalty in propulsive power has been attributed to a mature marine biofilm $[2,3]$.

Previously, biofouling has been controlled using toxic coatings, which have subsequently been shown to indiscriminately affect marine life. For instance, tributyltin (TBT) was widely used in coatings for its antifouling (AF) capacity. However, in September, 2008, further applications of TBT coatings were prohibited, in a treaty ratified by the International Maritime Organisation (IMO), due to its toxic effects in the wider marine environment, causing shell deformations in oysters, sex changes (imposex) in whelks and immune response, neurotoxic and genetic effects in other marine species [4]. TBT has been described as the most toxic substance ever deliberately introduced into the marine environment [4,5]. Therefore, the need for new, effective and environmentally friendly coatings has been the focus and challenge for the scientific community. The prohibition of the use of these toxic antifoulants has led to the search for bio-inspired AF strategies. Current attempts towards the production of alternative environmentally benign coatings involve biomimetic approaches [6,7], such as mimicking surfaces of marine organisms that are inherently foul-free and/or incorporating natural $\mathrm{AF}$ compounds into marine paints. It is estimated that AF coatings provide the shipping industry with annual fuel savings of $\$ 60$ billion and reduced emissions of 384 million and 3.6 million tonnes, respectively, for carbon dioxide and sulphur dioxide per annum [8].

In the marine environment, a wide variety of species demonstrate antifouling abilities by several means, e.g., the use of chemical [9] and physical [10] defences or symbiotic relationships between hosts (e.g., algae) and epibionts (e.g., bacteria) that prevent fouling. The inhibition of biofouling in a natural way, as observed in marine organisms, has triggered scientific interest, leading to the examination of marine natural products (NPs) as a possible basis for novel antifouling technology. Since the early 1980s, a great number of marine NPs have been assayed against organisms implicated in the biofouling process, and several reviews dealing with their potential use as novel antifouling biocides have been published [11-15]. Specifically, red algae (phylum: Rhodophyta) are known to exhibit antifouling properties [16,17]. It has also been reported that the red alga, C. crispus, exhibits antifouling activity against biofoulers [18,19]. While most studies have concentrated on marine eukaryotes as sources of NPs, bacteria have also been used by incorporating directly into coatings [20] and by extracting enzymes from non-marine isolates [21]. Recently, terrestrial NPs, pharmaceuticals and enzymes have been recognized as important sources of non-toxic antifoulants extensively reviewed by Qian et al. [22].

In the current work, three NPs were investigated for their anti-biofilm performance against two model biofilm forming bacteria (Cobetia marina and Marinobacter hydrocarbonoclasticus). A crude 
extract of the red seaweed, Chondrus crispus, was the marine NP tested, as it had been shown to have anti-microbial efficacy [23], while the terrestrial NPs were the pure compounds, (+)-usnic acid and juglone, isolated from a lichen and the black walnut, respectively $n$, which have been shown to have antibacterial efficacy [24,25]. The terrestrial products chosen for their AF potential have previously demonstrated antibacterial properties against medically relevant bacteria; however, their activity against marine biofilm forming species is reported here for the first time. The potential for antimicrobial attachment and biofilm formation was quantified through the in situ assessment of initial colonization of bacteria using imaging microplate reader technology combined with nucleic acid staining and epifluorescence microscopy.

\section{Results and Discussion}

\subsection{Growth Conditions (ASW vs. NSW)}

The initial attachment and growth conditions play a key role in cell biology, since the environment may affect the physiology and, therefore, the growth and kinetic response of an organism. Growth rates and doubling times for C. marina and M. hydrocarbonoclasticus grown under different media are shown in Table 1, while the growth kinetics can be seen in Figure 1. Firstly, we assessed whether it was reasonable to use artificial sea water (ASW) rather than natural sea water (NSW) for subsequent experiments. ASW has the advantage in that it is reproducible and not affected by seasonal or local manmade or natural environmental variations. Overall, when comparing equivalent peptone concentrations for the two different sea waters (ASW vs. NSW), no significant differences in planktonic growth rate were found. Therefore we concluded that using ASW as an alternative to NSW was acceptable to avoid seasonal and day-to-day variability in chemistry and nutrients. Regarding the peptone levels for the two media, it was found that the high peptone concentrations (artificial sea water peptone high (ASWPH), $18 \mathrm{~g} \mathrm{~L}^{-1}$ ) promoted higher bacterial growth when compared to the low concentrations (artificial sea water peptone low (ASWPL), $9 \mathrm{~g} \mathrm{~L}^{-1}$ ). Specifically, for $C$. marina, the growth rate was significantly higher for ASWPH when compared to ASWPL $(p<0.022)$ and ASW $(p<0.001)$. Similarly, for M. hydrocarbonoclasticus, the media with high peptone concentrations (ASWPH) illustrated the best growth performance (ASWPL, $p<0.001$, and ASW, $p<0.001$ ), i.e., contributing to the fastest growth rate. Furthermore, when comparing the sterilization procedures conducted on the ASW media, i.e., filtered vs. autoclaved, no significant difference in growth for both species was found. In the literature, autoclaving is routinely used as a medium sterilisation method for bacterial growth; however, to avoid changes in media chemistry, such as $\mathrm{pH}$ following autoclaving, the use of the filtration was decided to be the most appropriate procedure for the purposes of this work.

The degree of $C$. marina biofilm formation within the various media was in good agreement with the planktonic growth data (Figure 2). This species formed similar biofilms at the same peptone concentrations for both ASW and NSW. Again, consistent with the cell growth assays, lower biofilm growth was observed for the treatments without any supplemented carbon source (i.e., no peptone). In comparison to the growth rates (Table 1), there was generally good correlation between the test media/sterilisation and the biofilm formation, which demonstrated a good level of bioassay consistency for the ASW and NSW measurements. 
Table 1. Growth rates and doubling times for both species, Marinobacter hydrocarbonoclasticus (M. hydro) and Cobetia marina (C. mar), during the exponential growth phase using absorbance $\lambda=595 \mathrm{~nm}$ (Optical Density at $\lambda=595 \mathrm{~nm}\left(\mathrm{OD}_{595}\right)$ ), where: ASWPH, artificial sea water peptone high; ASWPL, artificial sea water peptone low; ASW, artificial sea water; FASWPH, filtered artificial sea water peptone high; NSWPH, natural sea water peptone high; NSWPL, natural sea water peptone low; and NSW, natural sea water.

\begin{tabular}{|c|c|c|c|c|c|c|c|c|}
\hline Species & & ASWPH & ASWPL & ASW & FASWPH & NSWPH & NSWPL & NSW \\
\hline$M$ & $\begin{array}{l}\text { Growth } \\
\text { rate }\left(h^{-1}\right)\end{array}$ & $0.115 \pm 0.008$ & $0.091 \pm 0.006$ & $0.022 \pm 0.010$ & $0.113 \pm 0.007$ & $0.109 \pm 0.009$ & $0.090 \pm 0.002$ & $0.013 \pm 0.002$ \\
\hline hydro & $\begin{array}{c}\text { Doubling } \\
\text { time }(\mathrm{h})\end{array}$ & $6.03 \pm 0.39$ & $7.59 \pm 0.52$ & $35.66 \pm 14.80$ & $6.11 \pm 0.36$ & $6.35 \pm 0.53$ & $7.63 \pm 0.22$ & $53.38 \pm 8.41$ \\
\hline \multirow{2}{*}{ C. mar } & $\begin{array}{l}\text { Growth } \\
\text { rate }\left(h^{-1}\right)\end{array}$ & $0.079 \pm 0.004$ & $0.072 \pm 0.002$ & $0.055 \pm 0.006$ & $0.075 \pm 0.002$ & $0.073 \pm 0.002$ & $0.075 \pm 0.002$ & $0.06 \pm 0.010$ \\
\hline & $\begin{array}{c}\text { Doubling } \\
\text { time (h) }\end{array}$ & $8.77 \pm 0.47$ & $9.54 \pm 0.30$ & $13.77 \pm 2.25$ & $9.21 \pm 0.31$ & $9.39 \pm 0.30$ & $9.15 \pm 0.27$ & $11.29 \pm 2.51$ \\
\hline
\end{tabular}

Figure 1. Bacterial growth kinetics over $24 \mathrm{~h}$ under different media, using optical density at $\lambda=595 \mathrm{~nm}\left(\mathrm{OD}_{595}\right)$, where: (a) Cobetia marina and (b) Marinobacter hydrocarbonoclasticus. ASWPH, artificial sea water peptone high; ASWPL, artificial sea water peptone low; ASW, artificial sea water; FASWPH, filtered artificial sea water peptone high; NSWPH, natural sea water peptone high; NSWPL, natural sea water peptone low; and NSW, natural sea water.
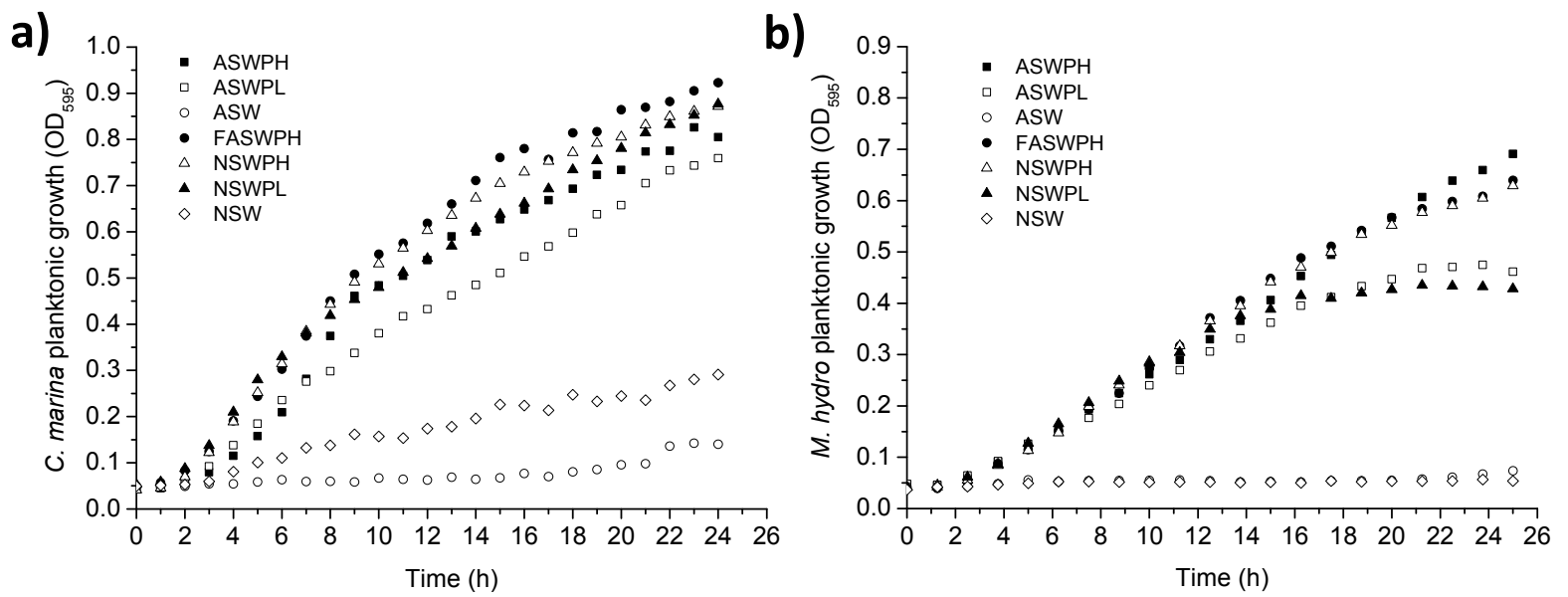

In contrast, $M$. hydrocarbonoclasticus showed an interesting difference in behaviour when comparing planktonic cells to biofilm growth (Figure 2). Although the lowest planktonic growth was found to be in unsupplemented ASW and NSW (Table 1), biofilm formation was highest in NSW. The NSW is likely to contain organic nutrients, which are naturally occurring in coastal waters, thus providing a source of nutrition that could possibly supply sufficient energy for the initial biofilm formation. The ASW did not trigger the same response, possibly because no organic nutrients were present. Additionally, the M. hydrocarbonoclasticus American Type Culture Collection (ATCC) 49840 strain used in this study was isolated near a petroleum refinery from sediments collected from 
polluted areas [26], and it is worth noting that in the current study, NSW was collected from Southampton Water, which is one of the largest harbours in England. In addition, the Fawley refinery, which is the largest in the UK, is also located in the wider Southampton Water vicinity; therefore, water collected from this area may be favourable to this strain, resulting in enhanced biofilm formations. Therefore, it is possible that $M$. hydrocarbonoclasticus might be able to utilize organics that C. marina could not.

Figure 2. Biofilm formation after $24 \mathrm{~h}$ for both species, M. hydrocarbonoclasticus and C. marina, where: ASWPH, artificial sea water peptone high; ASWPL, artificial sea water peptone low; ASW, artificial sea water; FASWPH, filtered artificial sea water peptone high; NSWPH, natural sea water peptone high; NSWPL, natural sea water peptone low; and NSW, natural sea water.

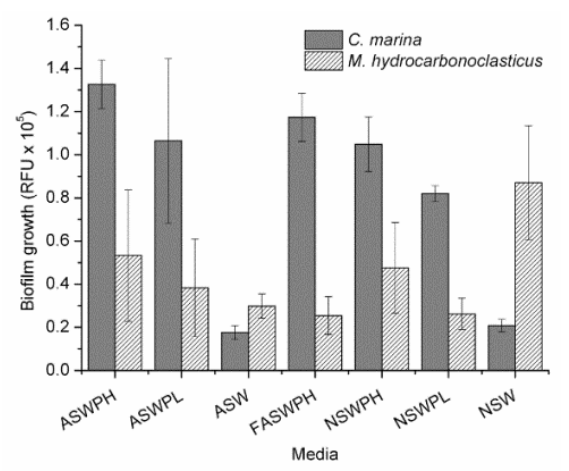

\subsection{Protocol Verification}

For biofilm work, microscopy is largely used to confirm both qualitative and quantitative data regarding biofilm structure and amount. While microplate reader technology is becoming increasingly popular due to its rapid and high-throughput properties, microscopy is still necessary to validate fluorescence and imaging data obtained from the microplate reader. For this reason, a validation test was conducted in order to determine the correlation between the two techniques, using microscopy to corroborate the less established plate reader technique. A strong positive linear correlation was obtained between the fluorescence intensity measured using the microplate reader and bacterial surface coverage as determined by epifluorescence microscopy for C. marina (Figure 3).

The use of microplate readers to quantify biofilm biomass in itself is not novel. O'Toole et al. [27] developed an extremely useful rapid screen for biofilm based on multiwell crystal violet (CV) staining. $\mathrm{CV}$ is a basic dye, which binds to negatively charged surface molecules and polysaccharides in extra polymeric substances (EPS) [28,29]. Nevertheless, fluorescence staining has advantages over conventional biological stains: (i) fluorescence is more sensitive than adsorption, so that an elution step is not required; reducing the number of rinse steps, lessening the possibility of undesired biofilm removal; (ii) fluorescence can be measured directly from opaque surfaces (which are the relevant surfaces for marine and industrial application), unlike absorption, which requires a transparent surface or stain elution; (iii) there are numerous fluorescent stains available that are highly specific for individual biofilm constituents, such as DNA, carbohydrates, proteins and viability, thus by choosing the appropriate combination of fluorophores and filter sets, various components of interest can be 
quantified separately, but in a single step; and (iv) fluorescence staining is compatible with the microplate reader, epifluorescence and confocal microscopy.

Figure 3. Syto ${ }^{\oplus} 9$ evaluation using two techniques, where $y$-axis data is obtained from the microplate-reader as a function of fluorescence intensity (RFU) and the $x$-axis is the same data obtained from epifluorescence microscopy, where ImageJ analysis was utilised to calculate the percentage of biofilm coverage on the 96-well plates. The bottom right insert illustrates a representative epifluorescence microscopy image of $C$. marina stained with Syto ${ }^{\circ} 9$ and attached on the bottom of the well ( $1 \mathrm{~h}$ experiment).

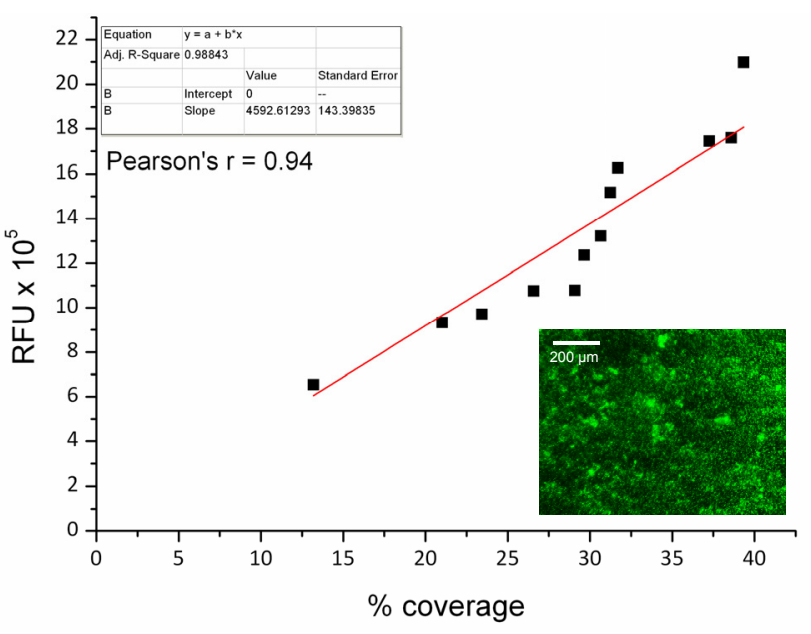

\subsection{Chondrus crispus Extracts and Bacterial Attachment}

C. crispus is commercially cultivated and available as a dried source and has been previously identified as having antifouling properties $[19,23,30]$. The ${ }^{1} \mathrm{H}$ NMR spectrum of the toluene-soluble fraction of a crude ethanolic extract of dried C. crispus (designated CCT) was recorded. The analysed sample consists of a mixture of compounds to which it is not possible to assign any specific chemical structure. However the spectrum indicates a high content of aliphatic carbon chains with features typical of fatty acid esters (triglycerides) and a small amount of unsaturation (see Figure 4). No signals were observed at chemical shifts $(\delta)$ above $8 \mathrm{ppm}$, indicating a lack of free carboxylic acid groups $(\delta>10 \mathrm{ppm})$. Fresh $C$. crispus has been shown to contain high levels of polyunsaturated fatty acid chains [31], so the apparent lack of unsaturation could result from the extended air drying process to which the seaweed has been subjected.

The major peaks in this spectrum can be assigned using the chemical shifts given in $[32,33]$, (referenced to $\mathrm{CHCl} 3$ at $\delta=7.28 \mathrm{ppm}$ ), Table 2 . 
Table 2. Assigments of ${ }^{1} \mathrm{H}$ NMR chemical shifts according to Guillén and Ruiz [32,33].

\begin{tabular}{ccc}
\hline Peak & ppm & Group \\
\hline $\mathrm{a}$ & 0.896 & $-\mathrm{CH}_{3}$ \\
$\mathrm{~b}$ & 1.272 & $-\left(\mathrm{CH}_{2}\right)_{n}-$ \\
$\mathrm{c}$ & 1.625 & $-\mathrm{OCO}-\mathrm{CH}_{2}-\mathrm{CH}_{2}-$ \\
$\mathrm{d}$ & 2.027 & $-\mathrm{CH}_{2}-\mathrm{CH}=\mathrm{CH}-$ \\
$\mathrm{e}$ & 2.331 & $-\mathrm{OCO}-\mathrm{CH}_{2}-$ \\
$\mathrm{f}$ & 4.168 & $-\mathrm{CH}_{2}-\mathrm{OCOR}$ \\
$\mathrm{g}$ & 5.360 & $-\mathrm{CH}=\mathrm{CH}-$ \\
\hline
\end{tabular}

Triglycerides are not known to exhibit marked AF effects; therefore, any anti-biofilm activity observed could be due to fatty acids produced by their hydrolysis in seawater or to other constituents of the crude extract not identifiable from this spectrum.

Figure 4. ${ }^{1} \mathrm{H}$ NMR spectrum of the Chondrus crispus organic solvent (toluene) extract.

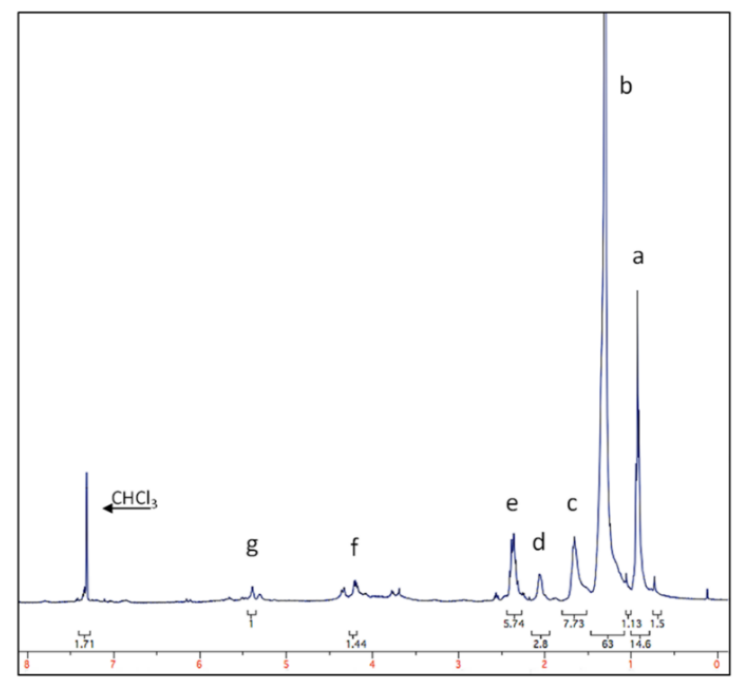

Figure 5a shows fluorescence intensity deriving from the attached cells in the individual wells (only one replica shown here) and their spatial distribution with respect to NP concentrations. Overall, for the CCT extract, bacterial attachment of $M$. hydrocarbonoclasticus was significantly increased when exposed to a concentration of $20 \mathrm{ppm}(p<0.001)$. However, the bacterial attachment was significantly reduced when $M$. hydrocarbonoclasticus was exposed to the higher CCT concentrations of $100 \mathrm{ppm}$ and $200 \mathrm{ppm}(p<0.001$ and $p<0.016$, respectively; Figure 5b). For C. marina, attachment was significantly higher at low CCT concentrations, i.e., $0.1 \mathrm{ppm}, 5 \mathrm{ppm}, 10 \mathrm{ppm}$ and $20 \mathrm{ppm}(p<0.010$, $p<0.002, p<0.001$ and $p<0.001$, respectively; Figure 5b). However, at the higher concentrations of $50 \mathrm{ppm}, 100 \mathrm{ppm}$ and $200 \mathrm{ppm}$, attachment was significantly inhibited $(p<0.010, p<0.020$ and $p<0.031$, respectively; Figure 5b). Although the overall accumulation for C. marina was reduced at high CCT concentrations, a concentration response was not observed, suggesting that this species was only affected by CCT concentrations between $20 \mathrm{ppm}$ to $50 \mathrm{ppm}$ and above (Figure $5 \mathrm{~b}$ ). The overall maximum attachment reductions were $35 \%$ and $50 \%$ for M. hydrocarbonoclasticus and C. marina, respectively (Figure 5c). 
Figure 5. The effect of $C$. crispus on $C$. marina and $M$. hydrocarbonoclasticus biofilm accumulation, where: (a) is the well scan images of individual wells (scan matrix dimension: $30 \times 30$, equivalent to a resolution of $213 \mu \mathrm{m} \times 213 \mu \mathrm{m}$; scan width: $6 \mathrm{~mm}$ ); (b) End point fluorescence intensity (units: relative fluorescent units, RFU). Positive/negative $(+/-)$ symbols indicate a significant increase $(+)$ or decrease $(-)$ in the attachment of the species when compared with the control at $95 \%$ confidence intervals. Syto9: excitation $\lambda=485 \mathrm{~nm}$, emission $\lambda=510 \mathrm{~nm}$. Error bars $\pm \mathrm{SD}$; (c) Attachment reduction according to RFU values, as a percentage of the control ( $0 \%$, dashed line), where negative values indicate increased attachment and positive values, reduction. CCT, C. crispus toluene soluble.

a)

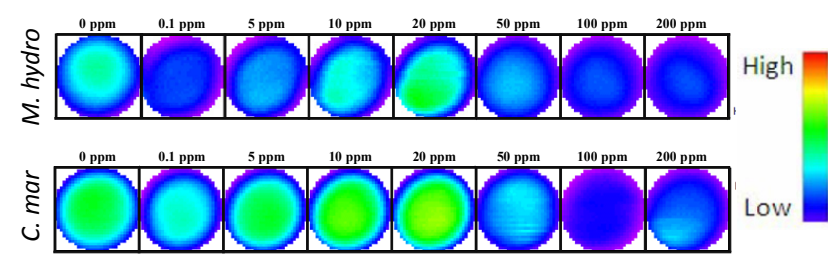

b)

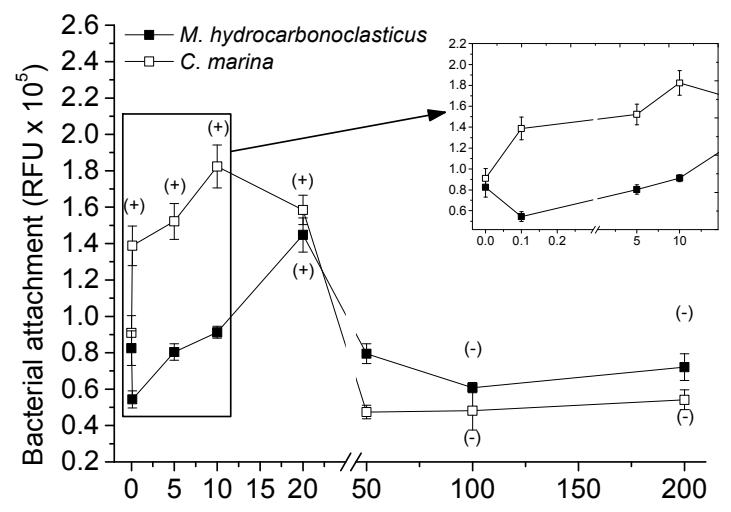

c)

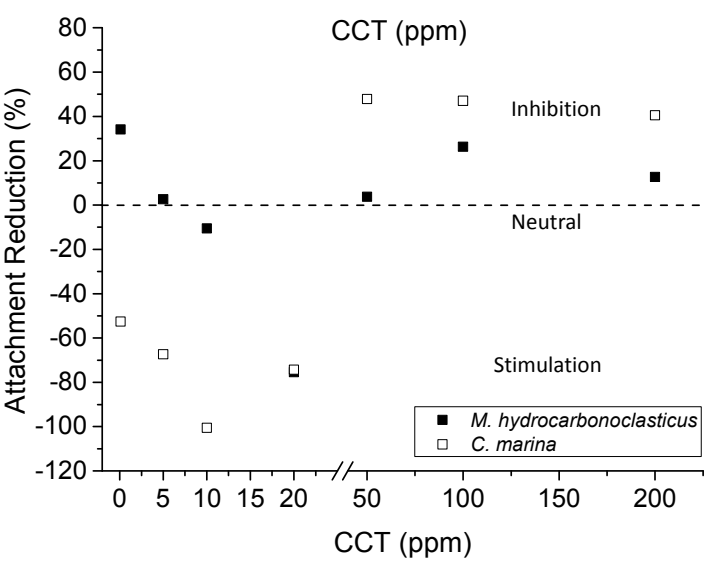

The reverse concentration response of enhanced $M$. hydrocarbonoclasticus and $C$. marina's attachment at low CCT concentrations (Figure 5) may be explained by the presence of hydrocarbons, such as triglycerides, as shown in Figure 4, which are known to be used by both species as the sole carbon source [26,34] — found within seaweeds. In nature, nutrient concentrations in the biofilm may become limiting, due to consumption and diffusion within the biofilm [35,36]. To overcome this limitation, bacteria can consume algal exudates, while the algae may benefit from the recycling of nutrients produced by the bacteria, including carbon [37]. This beneficial mutual relationship between bacteria and the algae is reported to result in a high bacterial activity within the biofilm [38-40]. 
Cox et al. [41] have also recently reported that a methanolic C. crispus crude extract enhanced both Gram-negative and Gram-positive bacterial growth of Listeria monocytogenes, Salmonella abony, Enterococcus faecalis and Pseudomonas aeruginosa.

In an AF context, the literature describes specific AF activities of $C$. crispus extracts $[18,19,23]$ and its by-products, such as hexose oxidase, which is used in a hydrogen peroxide-producing AF system [42]. In addition, Chambers et al. (2011) [23] reported that a crude ethanolic extract of dried C. crispus showed a greater AF effect than the extract derived from freshly harvested seaweed. However, the active components have yet to be identified, as the various NP extracts were not fully fractionated and assessed. Tannins are found in C. crispus extracts [41], and these are known to act against fouling organisms, such as barnacles [43]. An alternative antimicrobial mechanism has previously been proposed by Sullivan and Ikawa [44], who isolated and purified the enzyme, hexose oxidase, from C. crispus ([44-46]. Hexose oxidase is a copper-containing glycoprotein that catalyses the chemical reaction (Equation (1)):

$$
\text { D-glucose }+\mathrm{O}_{2} \leftrightarrow \text { D-glucono-1,5-lactone }+\mathrm{H}_{2} \mathrm{O}_{2}
$$

Metal component analysis of the enzyme has shown a copper content of $0.11 \%$, i.e., equivalent to 1100 ppm. Copper is known to be toxic to a variety of fouling organisms [47]; therefore, it may be hypothesised that the presence of hexose oxidase in $C$. crispus could negatively affect $M$. hydrocarbonoclasticus and C. marina, because of its copper content. Furthermore, enzymatic generation of hydrogen peroxide $\left(\mathrm{H}_{2} \mathrm{O}_{2}\right)$ has been shown to have a promising AF efficacy [42,48]. However, in the current study, the use of toluene as a solvent would possibly limit the enzyme extraction.

\subsection{Usnic Acid and Bacterial Attachment}

The well scans in Figure 6a show more prominent localised fluorescence intensities for M. hydrocarbonoclasticus in comparison to C. marina. Overall, the bacterial attachment bioassays demonstrated that $M$. hydrocarbonoclasticus was not affected by the addition of usnic acid at the low concentrations of $0.1 \mathrm{ppm}, 5 \mathrm{ppm}, 10 \mathrm{ppm}$ and $20 \mathrm{ppm}$. However, bacterial attachment was significantly inhibited in a concentration response way by usnic acid at concentrations of $30 \mathrm{ppm}$ and $40 \mathrm{ppm}(p<0.022$ and $p<0.001$, respectively; Figure $6 \mathrm{~b})$. The highest usnic acid concentration caused the highest attachment reduction $(65 \%)$ of all NPs tested in the current study for M. hydrocarbonoclasticus (Figure 6c). The effect of usnic acid on marine bacteria has not been reported previously. According to the literature, this compound is mostly active against Gram-positive species with little evidence of antimicrobial efficacy against Gram-negative bacteria [49]. The current results provide the first evidence of the effect of usnic acid on bacterial attachment for the Gram-negative marine bacterium, M. hydrocarbonoclasticus. For C. marina, no inhibitory effect was observed (Figure 6), rather an enhancement at almost all concentrations for usnic acid with an $80 \%$ to $110 \%$ increase in attachment for $0.1 \mathrm{ppm}$ to $10 \mathrm{ppm}$ (Figure 6c). We speculate that trace amounts of usnic acid, which is a quinone, might provide antioxidant benefits; it is also possible that there might be a signal effect similar to that in $P$. aeruginosa, where low concentrations of tobramycin stimulated 
biofilm growth [50]. While these hypotheses are interesting and potentially worth pursuing, they are outside the scope of work of the present study.

Figure 6. The effect of usnic acid on $C$. marina and $M$. hydrocarbonoclasticus attachment where: (a) is the well scan images of individual wells (scan matrix dimension: $30 \times 30$, equivalent to a resolution of $213 \mu \mathrm{m} \times 213 \mu \mathrm{m}$, scan width $6 \mathrm{~mm}$ ); (b) End point fluorescence intensity (units: relative fluorescent units, RFU). Positive/negative $(+/-)$ symbols indicate a significant increase $(+)$ or decrease $(-)$ in the attachment of the species when compared with the control at 95\% confidence intervals. Syto9: excitation $\lambda=485 \mathrm{~nm}$, emission $\lambda=510 \mathrm{~nm}$. Error bars $\pm \mathrm{STDEV}$; (c) Attachment reduction according to RFU values, as a percentage of the control ( $0 \%$, dashed line), where negative values indicate increased attachment and positive values, reduction.

a)

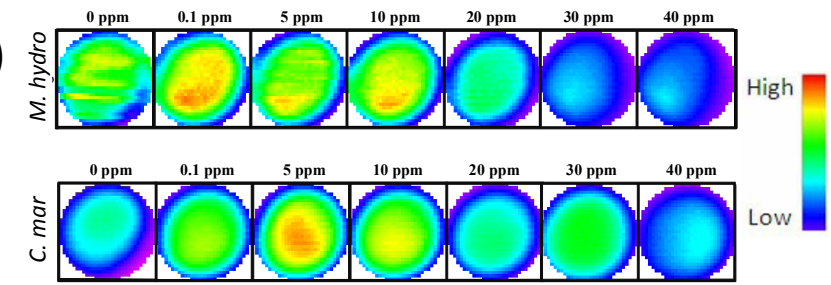

b)
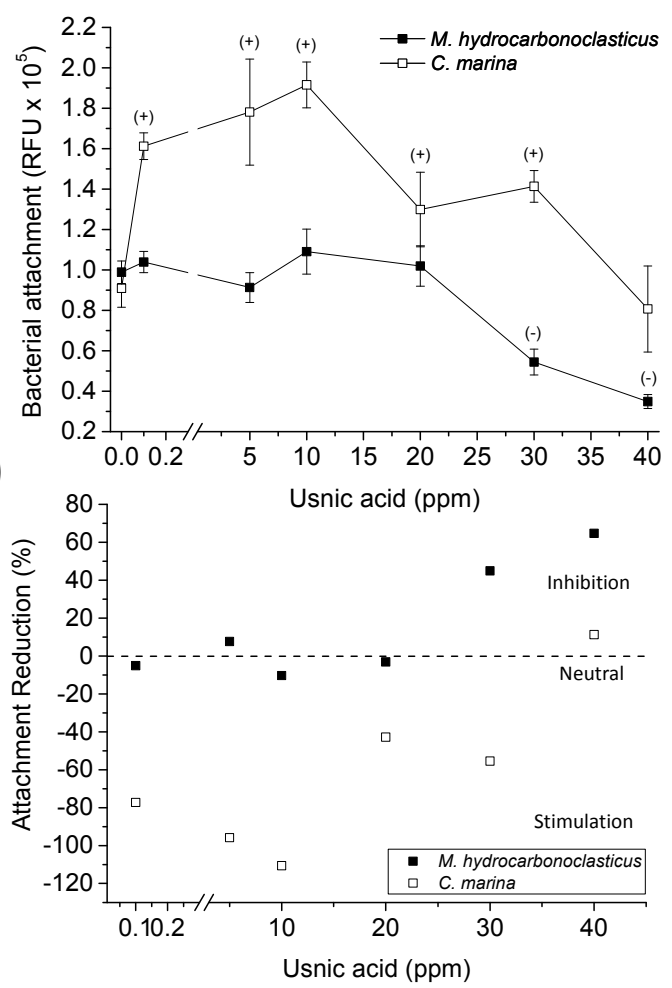

Usnic acid possesses antimicrobial activity against a number of planktonic Gram-positive bacteria [51], as well as antiviral activity. Although the mechanism of action of usnic acid against bacteria is still unknown, experimental evidence has illustrated that its antiviral activity is due to its ability to inhibit RNA transcription [52]. It has been shown that (+)-usnic acid and its isomer (-)-usnic acid are active against clinic isolates of E. coli and E. faecium (minimum inhibitory concentration MIC: $16 \mathrm{ppm}$ ) and clinical isolates of methicillin- or mupiricin-resistant Staphylococcus aureus (MIC: $16 \mathrm{ppm}$ [49]). In the same study, it was shown that both isomers exhibited profound activity against 
pathogenic anaerobic Bacteroides sp. Clostridium sp. and Propionibacterium sp. (MIC: $<16$ ppm, $4 \mathrm{ppm}$ and $2 \mathrm{ppm}$, respectively). Furthermore, Francolini et al. [24] reported an MIC of $32 \mathrm{ppm}$ for S. aureus, while the Gram-negative Pseudomonas aeruginosa showed an MIC at $256 \mathrm{ppm}$. In the same study, the effect of usnic acid (loaded on a polymer) on initial bacterial attachment using flow cells was assessed for $S$. aureus and $P$. aeruginosa, where it was found that usnic acid did not affect biofilm formation for $P$. aeruginosa. However, it significantly affected biofilm morphology (shape and thickness), indicating that the molecule may have interfered with signalling pathways.

\subsection{Juglone and Bacterial Attachment}

In Figure 7, juglone was shown to give a clear dose-dependent concentration response effect inhibiting M. hydrocarbonoclasticus attachment at $5 \mathrm{ppm}, 10 \mathrm{ppm}$ and $20 \mathrm{ppm}(p<0.007, p<0.005$ and $p<0.004$, respectively; Figure 7a,b). Similarly, C. marina's attachment is significantly reduced by juglone in a concentration response manner at $10 \mathrm{ppm}$ and $20 \mathrm{ppm}(p<0.050$ and $p<0.035$, respectively; Figure $7 \mathrm{~b})$. At the lowest juglone concentration $(0.1 \mathrm{ppm})$, there is an apparent increase in attachment (although not statistically significant) for both species, similar to the $C$. crispus extract. Overall, at the highest concentrations, this NP inhibited attachment by about $45 \%$ and $55 \%$ for M. hydrocarbonoclasticus and C. marina, respectively (Figure 7c). The current study reports, for the first time, the use of juglone against marine biofilm forming bacteria and illustrates an activity against bacterial attachment. In the context of AF strategies against marine biofilms, juglone appears to be a promising compound, which will be further investigated.

Juglone is widely reported to be growth-stunting to many plants types, where it exerts an allelopathic effect by inhibiting specific enzymes needed for metabolic function [53]. Quinone-type compounds have been widely identified and used as anticancer, antibacterial or antimalarial drugs and, also, as fungicides and herbicides [54]. Additionally, herbal preparations derived from juglone extracts have been used as hair dyes and skin colorants, in addition to being applied topically for the treatment of acne, inflammatory diseases, ringworm and fungal, bacterial or viral infections. Their therapeutic effect has been attributed to quinone cytotoxicity [55]. The overall toxicity mechanism of naphthoquinones has still not been clearly established, especially for prokaryotes. However, in general, juglone is classified as a strong redox cycler with high potential to react with oxygen and its reactive species. Therefore, it interferes with vital cell processes, such as respiration, photosynthesis, cell division and membrane transport [56,57].

The antimicrobial activity of naphthoquinones has been reported in several studies [25,58-61]. Juglone has been shown to act against the marine bioluminescent species, Vibrio fischeri, and the dinoflagellate, Glenodinium foliaceum [25]. Using the Lumitox ${ }^{\circledR}$ assay for $V$. fischeri (where the reduction of bioluminescence is linked to the inhibition of cellular activity, as a decreased rate of respiration), juglone exhibited bactericidal activity at concentrations as low as $0.005 \mathrm{ppm}$. In another study, the same naphthoquinone (5 hydroxy-1,4-napthoquinone) extracted from the heartwood of Caesalpinia sappan exhibited a good antibacterial performance against the intestinal Gram-positive bacterium, Clostridium perfringens [62]. Furthermore, a related US patent [63] claims solutions of juglone, or its derivatives in organic solvents as additives, for removing zebra mussels and quagga mussels from water intake pipes and various other underwater hard surfaces. 
Figure 7. The effect of juglone on $C$. marina and $M$. hydrocarbonoclasticus attachment where: (a) is the well scan images of individual wells (scan matrix dimension: $30 \times 30$, equivalent to a resolution of $213 \mu \mathrm{m} \times 213 \mu \mathrm{m}$, scan width $6 \mathrm{~mm}$ ); (b) End point fluorescence intensity (units: relative fluorescent units, RFU). Positive/negative (+/-) symbols indicate a significant increase $(+)$ or decrease $(-)$ in the attachment of the species when compared with the control at 95\% confidence intervals. Syto9: excitation $\lambda=485 \mathrm{~nm}$, emission $\lambda=510 \mathrm{~nm}$. Error bars $\pm \mathrm{STDEV}$; (c) Attachment reduction according to RFU values, as a percentage of the control ( $0 \%$, dashed line), where negative values indicate increased attachment and positive values, reduction.

a)

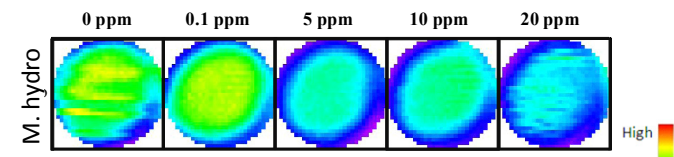

b)
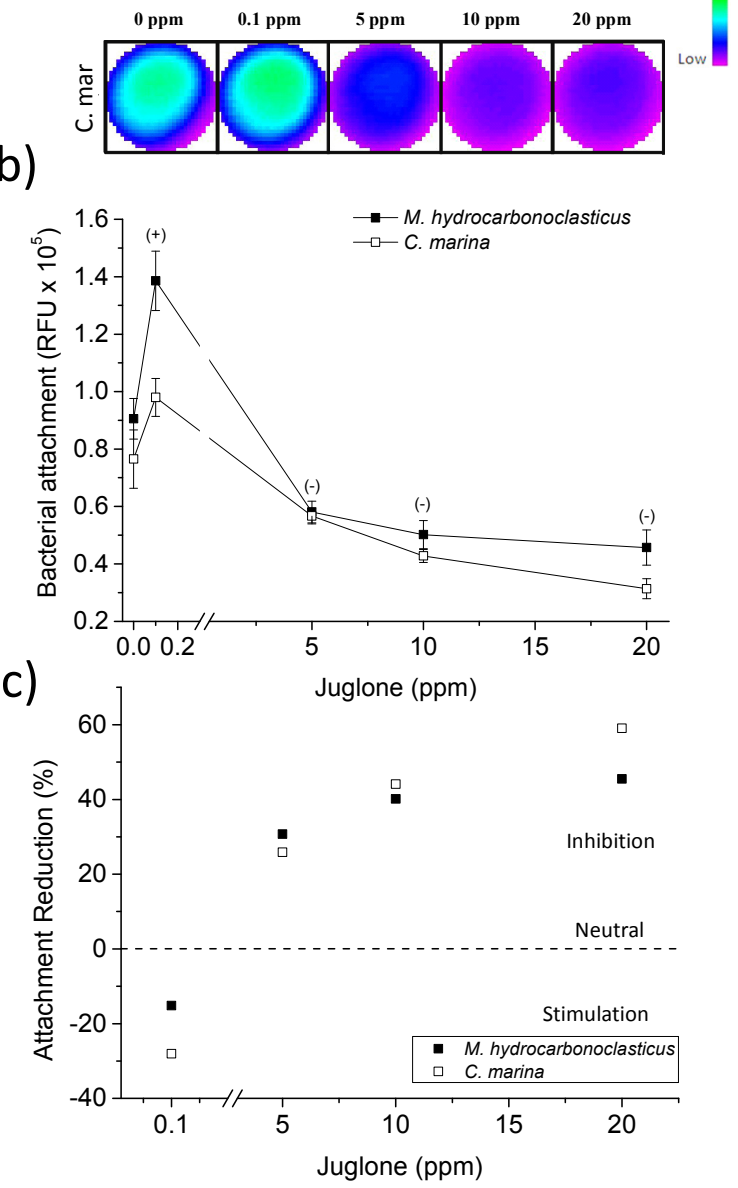

Overall, these results suggest that each of these terrestrial NPs can act as both an attachment promoter, as well as an inhibitor, depending on the NP concentration. This is supported by recently published studies, where it was reported that at high concentrations, antibiotics eradicate bacteria, while at low concentrations, biofilm formation is induced [50,64]; this phenomenon is often termed a hormetic response within the medical and toxicological context [65]. The results presented here, especially for juglone, appear to be promising, and we believe that, ultimately, a combination of surface texturing and chemistry will lead to the most effective AF performance. 


\subsection{Physico-Chemical Parameters}

An understanding of an AF compound's solubility in water is a necessity. Most frequently, this parameter is estimated by means of quantitative structure/activity relationships based on the $\log$ octanol-water partition coefficient $\left(\log K_{\text {ow }}\right)$. It is an important parameter used in the assessment of environmental fate and transport of organic chemicals, because the octanol phase is a surrogate for the lipid phase or organic carbon content of the environmental compartments. For comparison, the physical chemistry parameters relating to solubility for the two terrestrial compounds and four organic antifouling biocide molecules (tolylfluanid, dichlofluanid, DCOIT (4,5-dichloro- $N$-octyl4-isothiazolin-3-one) (SeaNine ${ }^{\mathrm{TM}}$ ) and cybutryne) that are approved under the Biocidal Products Directive 98/8/EC can be seen in Table 3.

Table 3. Calculated physico-chemical parameters (using Advanced Chemistry Labs Algorithm Version: v5.0.0.184 (Available online: https://ilab.acdlabs.com/iLab2/index. php, accessed on 20 June 2013) for natural products (NPs) used in the current work compared with approved commercial biocides.

\begin{tabular}{|c|c|c|c|c|c|c|}
\hline Parameters & Usnic acid & Juglone & Tolylfluanid & Dichlofluanid & $\begin{array}{c}\text { DCOIT } \\
\left(\text { SeaNine }^{\mathrm{TM}}\right)\end{array}$ & Cybutryne \\
\hline Solubility ${ }^{1}$ (ppm) & $420 *$ & $160 *$ & 39 & 58 & 63 & 390 \\
\hline $\log P^{2}$ & $\begin{array}{c}2.29 \\
(\mathrm{RI}=0.63)\end{array}$ & $\begin{array}{c}1.85 \\
(\mathrm{RI}=0.88)\end{array}$ & $\begin{array}{c}3.58 \\
(\mathrm{RI}=0.82)\end{array}$ & $\begin{array}{c}3.32 \\
(\mathrm{RI}=0.80)\end{array}$ & $\begin{array}{c}4.59 \\
(\mathrm{RI}=0.62)\end{array}$ & $\begin{array}{c}3.45 \\
(\mathrm{RI}=0.75)\end{array}$ \\
\hline $\mathrm{p} K \mathrm{a} 1^{3}$ & $5.3 \pm 0.8$ & $9.5 \pm 0.4$ & $-5.06 \pm 0.5$ & $-5.37 \pm 0.5$ & $-6.09 \pm 0.6$ & $4.12 \pm 0.1$ \\
\hline $\mathrm{p} K \mathrm{a} 2^{3}$ & $9.0 \pm 0.9$ & & $-16.79 \pm 0.7$ & $-16.89 \pm 0.7$ & & $-2.55 \pm 0.2$ \\
\hline $\mathrm{p} K \mathrm{a} 3^{3}$ & $12.0 \pm 0.9$ & & & & & \\
\hline $\log D$ at $\mathrm{pH} 8.2$ & -0.65 & 1.83 & 3.58 & 3.32 & 4.59 & 3.45 \\
\hline
\end{tabular}

Figure 8. $\log D$ values for juglone and usnic acid, where the vertical dashed line signifies the average sea water $\mathrm{pH}(8.2)$.

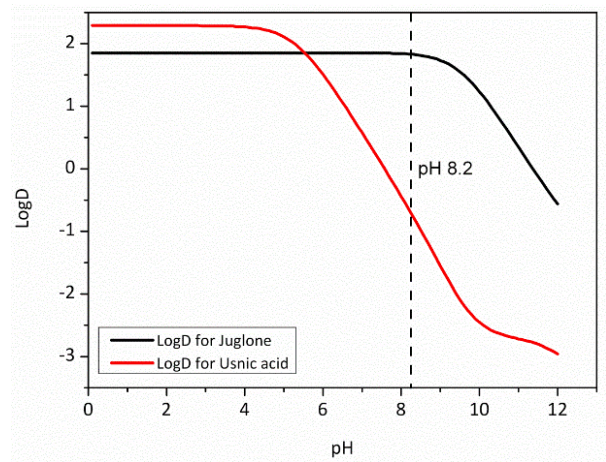

$\log P$ (also referred to as $\log K_{\text {ow }}$ ) is the logarithm of the partition coefficient of the unionised compound between octanol and water phases at equilibrium. $\log D$ is the $\log$ arithm of the distribution 
coefficient of an ionisable compound between octanol and water phases at defined $\mathrm{pH}$ values. The $\mathrm{p} K_{\mathrm{a}}$ parameter is the negative $\operatorname{logarithm}$ of the acid dissociation constant. Calculated $\log D$ values for juglone and usnic acid over the $\mathrm{pH}$ range of $0-12$ are plotted in Figure 8.

Partitioning of juglone into the water phase is low below $\mathrm{pH} 9$, while the more easily ionized usnic acid increasingly enters the water phase at $\mathrm{pH}>5$. At seawater $\mathrm{pH}$ (average seawater $\mathrm{pH}$ : 8.2), usnic acid is predominately partitioned into the water phase, while juglone remains in the octanol phase. For polystyrene microtiter plates, adsorption of lipophilic organic substances on to the well walls will occur, depending on the $\log P$ and/or $\log D$ values. Generally, it is considered that chemicals with a $\log P$ of greater than three should be regarded as problematic within microtiter assays depending on the stability of the concentration over the experimental timescales [67,68]. Although both NP compounds have $\log D$ values at $\mathrm{pH} 8.2$ lower than three ( -0.65 and 1.83 for usnic acid and juglone, respectively), there is greater potential for juglone to have adsorbed on to the well surfaces to some extent, changing the concentration within the ASW.

The $\log P$ of 1.83 , indicating a higher degree of hydrophilicity for juglone than for the commercial biocides, suggests that it has a lower potential for bioaccumulation and adsorption to sediments following release into the marine environment, as reported by [25]. In addition, the persistence of juglone has been shown to be dependent on the sterile status and light/dark conditions, for instance, a half-life of $12.7 \mathrm{~h}$ in sterile illuminated estuarine water $v s .87 \mathrm{~h}$ in non-sterile and dark conditions. By contrast, previously used commercial biocides, such as Diuron and Irgarol, have half-lives of 14 and 250 days, while their $\log P$ values are 2.8-3.95 and 2.8, respectively [69]. $\log P$, although it does not take $\mathrm{pH}$ into account, is often used as a relative indicator of the tendency of an organic compound to adsorb into marine sediments. Juglone, with a relatively $\operatorname{low} \log P$ value, is known to have limited bioaccumulation and a short half-life [25,70], and thus, it could be considered an appropriate candidate compound for AF coatings. From an effective AF perspective, if usnic acid were to be incorporated into a coating and released, due to its $\operatorname{low} \log D$, the leachant would predominantly exist in the aqueous phase, leading to rapid dispersion and dilution in the marine environment. Juglone with a higher $\log D$ may exist at relatively greater local concentrations at the coating surface and, thus, resulting in a greater potency. It would therefore be a more effective NP candidate for AF coatings [70].

\section{Materials and Methods}

\subsection{Natural Products}

Dried commercially available $C$. crispus (carrageen, supplied by Carraig Fhada Seaweed, Ireland) was used for preparing a natural product extract according to [23]. The organic extract was further purified by dissolving in toluene and discarding any insoluble residue (e.g., salts), before recovering the extract by evaporation of the solvent. Nuclear magnetic resonance (NMR) analysis of the purified extract dissolved in chloroform-d (99.96 atom\% D, Aldrich) was conducted using a Bruker DPX400 FT-NMR spectrometer.

A biologically active secondary metabolite identified in lichens of several species, including Usnea and Cladonia, is usnic acid [2,6-diacetyl-7,9-dihydroxy-8,9b-dimethyl-1,3(2H,9bH)-dibenzofurandione]. Usnic acid (Scheme 1) is a yellow pigment that exists in two enantiomeric forms, 
$(+)$-usnic acid and (-)-usnic acid, depending on the projection of the angular methyl group at the chiral $9 \mathrm{~b}$ position. While designated an acid, the molecule contains no carboxylic acid (-COOH) groups. However, the hydroxyl $(-\mathrm{OH})$ groups all have some acidic character, with the $-\mathrm{OH}$ at position 3 being the most strongly acidic ( $\left.\mathrm{p} K_{\mathrm{a}} 4.4\right)$, due to an inductive effect of the keto group [71]. The solubility of usnic acid in pure water is $<0.01 \mathrm{~g} / 100 \mathrm{~mL}$ [72], but will be higher in seawater ( $\mathrm{pH} 8$ ), owing to the ionisation of the $-\mathrm{OH}$ groups. Crude lichens have been used in folk medicine since ancient times to treat various medical conditions. One biologically active secondary metabolite identified in lichens of several species, including Usnea and Cladonia, is usnic acid [2,6-diacetyl-7,9-dihydroxy-8,9bdimethyl-1,3(2H,9bH)-dibenzo-furandione].

Juglone [5-hydroxy-1,4-naphthalenedione] (Scheme 1) occurs naturally in all parts of the black walnut (Juglans nigra) tree, especially the nut husks and roots. Juglone is an inhibitor of respiration, which deprives other plants of the energy needed for metabolic activity, and plants grown near black walnut trees exhibit symptoms, such as foliar yellowing, wilting and eventual death [73]. Juglone is used in consumer products, such as herbal medicines and hair dye formulations, although it is potentially toxic to humans [74].

Scheme 1. Molecular structures of the terrestrial natural products use in the current study.

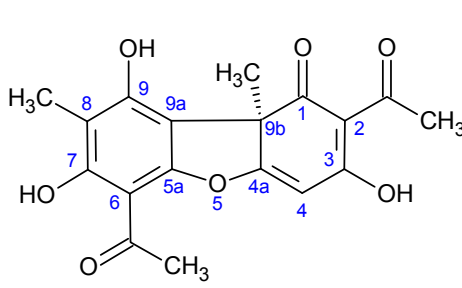

(I) Usnic acid<smiles>O=C1C=CC(=O)c2c(O)cccc21</smiles>

(II) Juglone

Both juglone and usnic acid were purchased from Sigma-Aldrich ${ }^{\circledR}$ (AR grade, cat. Nos. H47003 and 329967, respectively). This work has only investigated the (+)-usnic acid enantiomer.

\subsection{Marine Bacteria Test Species}

The marine biofilm forming species used in this study were Cobetia marina (ATCC 25374) and Marinobacter hydrocarbonoclasticus (ATCC 49840), obtained from the American Type Culture Collection (ATCC). Both species have previously been used as models in studies on initial attachment of marine bacteria to surfaces [75-77]. Marine bacteria species are commonly cultured in marine broth, which includes peptone (P) as a carbon source recommended for ATCC species, in either sterilised natural sea water (NSW) or artificial sea water (ASW). Both species were kept as frozen stock aliquots in sea salts (ASW, Sea Salts S9883, Sigma Aldrich, St. Luis, MO, USA) plus 18 g L $^{-1}$ peptone, abbreviated as SSP [77], with $10 \%$ glycerol added and preserved at $-80{ }^{\circ} \mathrm{C}$. The cryopreserved culture stocks were plated on marine agar (BD DifcoTM Marine Agar 2216, Franklin Lakes, NJ, USA) placed in a cooled incubator (Binder KB115, Binder, Mittleren, Germany) at $28{ }^{\circ} \mathrm{C}$. Young colonies were formed within $42 \mathrm{~h}$ after incubation. A single colony was then picked using a sterile inoculation loop and transferred into sterile SSP, where the bacteria were left to grow overnight. The recommended temperature range for both species from ATCC is $26-30{ }^{\circ} \mathrm{C}$. 


\subsection{Culture Conditions and Choice of Media}

New cultures of $M$. hydrocarbonoclasticus and $C$. marina from frozen stock aliquots were plated on marine agar for 3 days. After 3 days, individual colonies were inoculated in SSP and incubated at $28{ }^{\circ} \mathrm{C}$ under agitation $(80 \mathrm{rpm})$, overnight. The cultures were then washed in order to avoid any medium carry over using the following steps: $40 \mathrm{~mL}$ of the overnight cultures were placed into $50 \mathrm{~mL}$ centrifuge tubes, and the cells were centrifuged at $4000 \mathrm{rpm}$ for $8 \mathrm{~min}$ at $6{ }^{\circ} \mathrm{C}$. Once the cells were centrifuged down, creating a pellet at the bottom of the centrifuge tube, the supernatant (medium) was discarded, and sterile ASW was introduced. The cells were then re-suspended, using a vortex mixer, in ASW and re-centrifuged.

The differences between ASW and NSW compositions may vary greatly, due to naturally occurring nutrient seasonality observed in the NSW, plus variable salinity and pollutant levels at the sampling location. NSW for this study was collected from Southampton Water, summer, 2011. For laboratory-based assays, ASW is generally considered to provide greater controllability over the aforementioned water properties, and it was therefore decided to conduct a series of tests comparing the different experimental media, i.e., NSW vs. ASW, and the levels of carbon typically used in bacterial bioassay testing. The sterilisation procedure was also assessed in the current experiments, i.e., media autoclaved vs. sterile filtered through a $0.2 \mu \mathrm{m}$ pore size (Steritop ${ }^{\mathrm{TM}}$ Millipore ${ }^{\circledR}$ Filter Units, Billerica, MA, USA). This was done for two main reasons: (1) autoclaving ASW (without peptone) produced precipitates in the solution and (2) preliminary experiments illustrated a significant change in the medium's pH (the solution becoming more alkaline) after autoclaving. NSW was collected from Southampton Water, UK, in May, 2010, and glass micro fibre filters GF/F were used to remove coarse particulates prior to the sterilisation procedures. The complete experimental matrix of the media tested can be seen in Table 4 .

Table 4. Experimental media for C. marina and M. hydrocarbonoclasticus. ASW, artificial sea water; NSW, natural sea water; $\mathrm{P}$, peptone; $\mathrm{H}$, high concentration $\left(18 \mathrm{~g} \mathrm{~L}^{-1}\right)$; and $\mathrm{L}$, low concentration $\left(9 \mathrm{~g} \mathrm{~L}^{-1}\right)$. SSP, sea salts and peptone.

\begin{tabular}{cccc}
\hline Water & Peptone $\left(\mathbf{g ~ L}^{-\mathbf{1}}\right)$ & Sterilisation & Acronym \\
\hline \multirow{4}{*}{ ASW } & 18 & Autoclaved & ASWPH \\
& 9 & Autoclaved & ASWPL \\
& 0 & Autoclaved & ASW \\
& 18 & Filtered $(0.2 \mu \mathrm{m})$ & ASWPH \\
\hline \multirow{3}{*}{ NSW } & 18 & Filtered $(0.2 \mu \mathrm{m})$ & NSWPH \\
& 9 & Filtered $(0.2 \mu \mathrm{m})$ & NSWPL \\
\cline { 2 - 4 } & 0 & Filtered $(0.2 \mu \mathrm{m})$ & NSW \\
\hline
\end{tabular}

* ASWPH $=$ SSP.

\subsubsection{Planktonic Growth on Different Media}

First, we assessed growth on different media in order to choose the most appropriate for subsequent routine testing. Wells of a 96-well plate (optical bottom plated with polymer base, black, Nunc ${ }^{\mathrm{TM}}$ ) were conditioned by the addition of $190 \mu \mathrm{L}$ of the experimental media $1 \mathrm{~h}$ before bacterial inoculation. Following the well conditioning, $10 \mu \mathrm{L}$ of washed cells were inoculated into the wells to achieve a 
final volume of $200 \mu \mathrm{L}$ per well. Seven different experimental media were tested, as outlined in Table 4.

Five replicas for each treatment were performed. Four replicas of un-inoculated wells were also used as blanks for possible procedural contamination and background signals. Cell growth experiments were performed for a total duration of $24 \mathrm{~h}$ at $28{ }^{\circ} \mathrm{C}$, and absorbance at $\lambda=595 \mathrm{~nm}$ (commonly referred to as optical density, $\mathrm{OD}_{595}$ ) was measured using a microplate reader (FLUOstar Omega, BMG LABTECH, Offenburg, Germany). The optical density $\left(\mathrm{OD}_{595}\right)$ was measured every $15 \mathrm{~min}$. The software used was Mars Data Analysis Software, Version 2.00 (Omega, BMG LABTECH, Offenburg, Germany).

\subsubsection{Biofilm Growth under Different Medium Conditions Using Nucleic Acid Staining}

To quantify the amount of biofilm at the end point of the growth period, the media in the 96-well microplates were removed, and each well was individually rinsed (by pipetting) twice with ASW in order to remove planktonic cells. After the washing steps, the biofilm was stained with Syto $^{\odot} 9$ (Molecular Probes ${ }^{\circledR}$, Eugene, OR, USA), according to the manufacturer's instructions, i.e., $2 \mu \mathrm{L}$ of the Syto ${ }^{\odot} 9$ (provided at $5 \mathrm{mM}$ in $100 \%$ DMSO) per $1 \mathrm{~mL}$ of Phosphate Buffer Saline (pH 7.4). Syto ${ }^{\odot} 9$ is a green fluorescent intercalating membrane permeable stain, which is expected to stain all cells. Following the staining procedure, the plates were incubated in the dark at $28{ }^{\circ} \mathrm{C}$ for $20 \mathrm{~min}$. The microplate reader multichromatic filters were calibrated to suit the excitation and emission wavelengths of Syto $^{\odot} 9$. Syto ${ }^{\odot} 9$ fluorescence intensity and imaging were used to quantify biofilm biomass (see the below details on wavelengths).

Following the incubation period, the wells were again washed twice with ASW to remove excess stain. Finally, $100 \mu \mathrm{L}$ of ASW were added to the wells to prevent biofilm dehydration during the measurements. The microplate reader was utilised for direct end point measurements (relative fluorescence units, RFU) to allow high-resolution analysis of fluorescence intensity, which was conducted using $\lambda_{\mathrm{EX}}=485 \mathrm{~nm}$ (for excitation) and $\lambda_{\mathrm{EM}}=510 \mathrm{~nm}$ (for emission).

\subsection{Attachment Bioassays}

The 96-well microplates (optical bottom plated with polymer base, black, Nunc ${ }^{\mathrm{TM}}$ ) were inoculated with $200 \mu \mathrm{L}$ of ASW for $1 \mathrm{~h}$ prior to bacterial inoculation in order to condition the wells. After $1 \mathrm{~h}$, the wells were emptied, and $199 \mu \mathrm{L}$ of the prepared bacteria (washed according to the previous section and re-suspended in ASW at a starting concentration of $\mathrm{OD}_{595}=0.2$ ) were inoculated in each well. In order to fully dissolve the natural products (NPs), 100\% dimethyl sulfoxide (DMSO) was used as the solvent to produce a stock solution of $40,000 \mathrm{ppm}$, while serial dilutions in DMSO (100 vol\%, all percentages by volume) followed to give the final concentrations listed in Table 5. The concentrations used were comparable with those reported in the antifouling literature, typically in the order of $1 \mathrm{ppm}$ to $1000 \mathrm{ppm}[78,79]$. A $1 \mu \mathrm{L}$ aliquot from each NP stock solution was added to the wells, giving a final well volume of $200 \mu \mathrm{L}$. Using the NP dissolved in a small volume $(1 \mu \mathrm{L})$ of DMSO was found to be the preferred option, as it allowed a low final DMSO concentration $(0.5 \%)$ in the wells. DMSO can be bacteriostatic at high concentrations of $12.5 \%-20 \%$ [80,81]; therefore the lower its concentration, the lower the risk of bacterial toxicity due to this solvent, rather than the NP itself. Control wells with 
no NP validated that $0.5 \%$ DMSO did not affect bacterial attachment. Each NP concentration was replicated five times, while for each concentration, three uninoculated wells served as blanks. Controls included: bacteria in ASW and bacteria in ASW plus 0.5\% DMSO. In Table 5, the complete experimental matrix for the NPs is shown.

Table 5. Natural products (NP) used to assess bacterial attachment where, JUG, juglone;

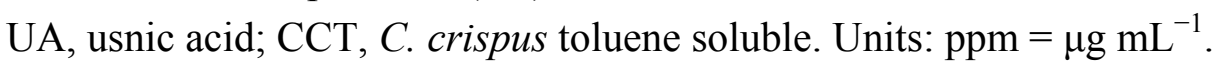

\begin{tabular}{cc}
\hline NP & Concentration (ppm) \\
\hline CCT & $0.1,5,10,20,50,100,200$ \\
UA & $0.1,5,10,20,30,40$ \\
JUG & $0.1,5,10,20$ \\
\hline
\end{tabular}

Following bacteria inoculation and NP additions, the 96-well plates were incubated for $1 \mathrm{~h}$ at $28{ }^{\circ} \mathrm{C}$ under static conditions. The attachment assay was carried out for $1 \mathrm{~h}$ [77]. After the incubation time, $\mathrm{OD}_{595}$ measurements were taken to establish the planktonic growth, and no significant differences were found between the treatments $(p>0.05)$. Then, the NPs and controls in the 96-well plates were removed, and each well was individually rinsed (by pipetting) twice with ASW in order to remove any planktonic cells. Staining with Syto ${ }^{\circledR} 9$ was followed (as explained in the previous section) to achieve bacterial attachment quantification. In addition, the well scanning capability of the microplate reader was used for spatial visualization of fluorescence intensity emitted by newly attached bacteria in individual wells, allowing for identification of heterogeneous biofilm structures and their distribution (e.g., whether there is marked attachment on the well walls, which is often considered an issue in well plate assays). Each well was scanned to produce an image of the newly attached formations (scan matrix dimension: $30 \times 30$, equivalent to a resolution of $213 \mu \mathrm{m} \times 213 \mu \mathrm{m}$, and a scan width of $6 \mathrm{~mm}$ ). The main advantage of the imaging utility is its sufficient sensitivity to identify biofilm features, as well as the plethora of sampling points within the well, providing a very accurate measurement representative of the entire well. Importantly, the fluorescence signals from the walls can be excluded, providing, in this way, accurate measurements exclusively from the well's bottom. The percentage of attachment reduction $(R \%)$ was determined by the following expression (Equation (2)):

$$
R \%=\left(\frac{(\text { Con }-\operatorname{Exp})}{\operatorname{Con}}\right) \times 100
$$

where, $C o n=$ control (i.e., no compound added) and $\operatorname{Exp}=$ experimental (i.e., with compounds).

\subsection{Syto ${ }^{\odot} 9$ Validation (Microplate Reader-Epifluorescence Microscopy)}

Separate attachment experiments were conducted (according to the above protocol) to compare/validate microplate reader measurements of Syto ${ }^{\circ} 9$ against epifluorescence microscopy. At the experimental end point $(1 \mathrm{~h})$ and following the Syto ${ }^{\circ} 9$ staining, the 96 -well plates were placed under an epifluorescence microscope for visualisation using the $10 \times$ magnification objective lens (EVOSfl, AMG, Life Technologies, Carlsbad, CA, USA) and the standard green-fluorecent-pigment (GFP) light-emitting diode (LED) light cube $\left(\lambda_{\mathrm{EX}}: 370 \mathrm{~nm}-\lambda_{\mathrm{EM}}: 525 \mathrm{~nm}\right)$. The images were acquired using the microscope's built-in camera (a high sensitivity interline charge-coupled device camera). 
Five replica images were taken for each well and within a defined region of interest (ROI), avoiding the well walls, resulting in a total of $N=45$ per treatment. Image analysis was conducted using ImageJ (Biophotomics, Available online: http://rsbweb.nih.gov/ij/plugins/mbf/index.html), where images were transformed into a binary format, i.e., either 0 or 255, and the percentage of coverage of attached bacteria was quantified. The calculated percentage coverage from each well was then plotted against its equivalent datum obtained from the plate reader, i.e., average fluorescence intensity (RFU).

Once the percentage of coverage of bacteria attached on the surface (bottom of the well) was calculated for each well, data were plotted against the average fluorescence intensity (RFU) obtained from the plate reader for the same well.

\subsection{Physico-Chemical Parameters}

The physico-chemical parameters, solubility, $\log P, \mathrm{p} K \mathrm{a}^{1-3}$ and $\log D$ at $\mathrm{pH} 8.2$, for the four organic antifouling biocide molecules: tolylfluanid, dichlofluanid, DCOIT (SeaNine ${ }^{\mathrm{TM}}$, DOW Chemical Company, Midland, MI, USA) cybutryne and the two terrestrial NPs, juglone and usnic acid, were calculated using the online version of ACD/Labs Algorithm Version: v5.0.0.184 (https://ilab.acdlabs.com/iLab2/index.php).

\subsection{Statistical Analysis}

Differences in $\mathrm{OD}_{595}$ and RFU values between experimental and controls were assessed by applying one-way ANOVA. To establish the homogeneity of variances, Levene's test of equal variances was applied. Where homogeneity of variances was not met, the non-parametric Kruskal-Wallis test was applied. Statistical analysis was performed using SPSS software (version 17.0, IBM, New York, NY, USA). Differences were considered statistically significant for $p<0.05$.

\section{Conclusions}

The toluene soluble part of C. crispus (CCT) was found to inhibit bacterial attachment at concentrations of 50-200 ppm for C. marina and 100-200 ppm for M. hydrocarbonoclasticus. However, low CCT concentrations appeared to have promoted M. hydrocarbonoclasticus' attachment, suggesting an alternative activity of this extract in a concentration-dependent manner. Usnic acid was found to be active against $M$. hydrocarbonoclasticus, deterring biofilm attachment at concentrations of 30 and $40 \mathrm{ppm}$, while $C$. marina was not inhibited by this natural product. The best anti-biofilm performance was observed for the terrestrial pure compound, juglone. This NP inhibited both $M$. hydrocarbonoclasticus's and C. marina's attachment, in a concentration response manner, at concentrations as low as $5 \mathrm{ppm}$ to $20 \mathrm{ppm}$. In addition to existing AF bioassays against marine biofilms (such as OD, visual observations or simple staining), this study has explored the use of nucleic acid staining for the in situ quantification of newly attached bacteria $(1 \mathrm{~h})$ and successfully correlated the two principal techniques for bacterial and biofilm work, the microplate reader and epifluorescence microscopy. 


\section{Acknowledgments}

The authors acknowledge the financial support of the Defence Science and Technology Laboratory (DSTL), which is part of the UK's Ministry of Defence, and the European Defence Agency (EDA).

\section{Conflicts of Interest}

The authors declare no conflict of interest.

\section{References}

1. Salta, M.; Wharton, J.A.; Blache, Y.; Stokes, K.R.; Briand, J.F. Marine biofilms on artificial surfaces: Structure and dynamics. Environ. Microbiol. 2013, doi:10.1111/1462-2920.12186.

2. Schultz, M.P. Frictional resistance of antifouling coating systems. J. Fluids Eng. 2004, 126, 1039-1047.

3. Schultz, M. Effects of coating roughness and biofouling on ship resistance and powering. Biofouling 2007, 23, 331-341.

4. International Convention on the Control of Harmfull Anti-fouling Systems on Ships. Available onlin: http://www.google.com.hk/url? sa=t\&rct=j\&q=International\%20Convention\%20on\%20the $\%$ 20Control $\% 20$ of $\% 20$ Harmfull\%20Anti-fouling\%20Systems $\% 20$ on $\% 20$ ships $\% 20$ AFS $\% 2$ FCO

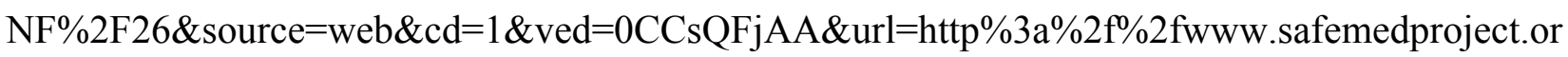
$\mathrm{g} \% 2$ fdocuments $\% 2$ freference-documents $\% 2$ ftask1.1-important-documentation-for-maritime-admi nistrations $\% 2$ fafs $\% 2$ fafs-convention-english-version $\% 2$ fat_download $\% 2$ ffile\&ei $=\mathrm{g} 1 \mathrm{RbUvudBOP}$ RiAfR_oDgBw\&usg=AFQjCNGvTjN1Gq_Uh8yZwRJUU_KHk7YTXw\&bvm=bv.53899372,d.a Gc\&cad=rjt (accessed on 14 October 2013).

5. Evans, S.M.; Leksono, T.; McKinnell, P.D. Tributyltin pollution: A diminshing problem following legislation limiting the use of TBT-based anti-fouling paints. Mar. Pollut. Bull. 1995, 30, 14-21.

6. Salta, M.; Wharton, J.A.; Stoodley, P.; Dennington, S.P.; Goodes, L.R.; Werwinski, S.; Mart, U.; Wood, R.J.; Stokes, K.R. Designing biomimetic antifouling surfaces. Philos. Trans. R. Soc. A 2010, 368, 4729-4754.

7. Scardino, A.J.; de Nys, R. Mini review: Biomimetic models and bioinspired surfaces for fouling control. Biofouling 2011, 27, 73-86.

8. IMO, International Shipping and World Trade Facts and figures. Maritime Knowledge Centre. Available online: http://80.33.141.76/esatdor/index.php?option=com_content\&view=article\& $\mathrm{id}=94$ :international-shipping-and-world-trade-facts-and-figures-2009-\&catid=11:key-eu-data-sour ces\&Itemid=17 (accessed on 14 October 2013).

9. Burns, E.; Ifrach, I.; Carmeli, S.; Pawlik, J.R.; Ilan, M. Comparison of anti-predatory defenses of Red Sea and Caribbean sponges. I. Chemical defense. Mar. Ecol. Prog. Ser. 2003, 252, 105-114.

10. Burns, E., Ilan, M. Comparison of anti-predatory defenses of Red Sea and Caribbean sponges. II. Physical defense. Mar. Ecol. Prog. Ser. 2003, 252, 115-123. 
11. Davis, A.R.; Targett, N.M.; McConnell, O.J.;Young, C.M. Epibiosis of marine algal and benthic invertebrates: Natural products chemistry and other mechanisms inhibiting settlement and overgrowth. Bioorgan. Mar. Chemistry, 1989, 3, 85-114.

12. Abarzua, S.; Jakubowski, S. Biotechnological investigation for the prevention of biofouling. 1. Biological and biochemical principles for the prevention of biofouling. Mar. Ecol. Prog. Ser. 1995, 123, 301-312.

13. Clare, A.S. Marine natural product antifoulants: status and potential. Biofouling 1996, 9, 211-229.

14. Omae, I. General aspects of tin-free antifouling paints. Chem. Rev. 2003, 103, 3431-3448.

15. Fusetani, N. Antifouling marine natural products. Nat. Prod. Rep. 2011, 28, 400.

16. De Nys, R.; Steinberg, P.D.; Willemsen, P.; Dworjanyn, S.A.; Gabelish, C.L.; King, R.J. Broad spectrum effects of secondary metabolites from the red alga delisea pulchra in antifouling assays. Biofouling 1995, 8, 259-271.

17. Sudatti, D.; Rodrigues, S.; Coutinho, R.; da Gama, B.A.P.; Salgado, L.T.; Filho, G.M.A.; Pereira, R.C. Transport and defensive role of elatol at the surface of the red seaweed Laurencia obtusa (Ceramiales, Rhodophyta). J. Phycol. 2008, 44, 548-591.

18. Hellio, C.; Bremer, G.; Pons, A.M.; le Gal, Y.; Bourgougnon, N. Inhibition of the development of microorganisms (bacteria and fungi) by extracts of marine algae from Brittany, France. Appl. Microbial. Biotechnol. 2000, 54, 543-549.

19. Hellio, C.; Marechal, J.P.; Véron, B.; Bremer, G.; Clare, A.S.; le Gal, Y. Seasonal variation of antifouling activities of marine algae from the Brittany coast (France). Mar. Biotechnol. 2004, 6, $67-82$.

20. Burgess, J.G.; Boyd, K.G.; Armstrong, E.; Jiang, Z.; Yan, L.; Berggren, M.; May, U.; Pisacane, T.; Granmo, A.; Adams, D.R. The development of a marine natural product-based antifouling paint. Biofouling 2003, 19, 197-205.

21. Shields, R.C.; Mokhtar, N.; Ford, M.; Hall, M.J.; Burgess, J.G.; ElBadawey, M.R.; Jakubovics, N.S. Efficacy of a marine bacterial nuclease against biofilm forming microorganisms isolated from chronic rhinosinusitis. PLoS One 2013, 8, e55339.

22. Qian, P.Y.; Xu, Y.; Fusetani, N. Natural products as antifouling compounds: Recent progress and future perspectives. Biofouling 2010, 26, 223-234.

23. Chambers, L.D.; Hellio, C.; Stokes, K.R.; Dennington, S.P.; Goodes, L.R.; Wood, R.J.K.; Walsh, F.C. Investigation of Chondrus crispus as a potential source of new antifouling agents. Int. Biodeterior. Biodegrad. 2011, 65, 939-946.

24. Francolini, I.; Norris, P.; Piozzi, A.; Donelli, G.; Stoodley, P. Usnic acid, a natural antimicrobial agent able to inhibit bacterial biofilm formation on polymer surfaces. Antimicrob. Agents Chemother. 2004, 48, 4360-4365.

25. Wright, D.A.; Dawson, R.; Cutler, S.J.; Cutler, H.G.; Orano-Dawson, C.E.; Graneli, E. Naphthoquinones as broad spectrum biocides for treatment of ship's ballast water: Toxicity to phytoplankton and bacteria. Water Res. 2007, 41, 1294-1302.

26. Gauthier, M.J.; Lafay, B.; Christen, R.; Fernandez, L.; Acquaviva, M.; Bonin, P.; Bertrand, J.C. Marinobacter hydrocarbonoclasticus gen. nov., sp. nov., a new, extremely halotolerant, hydrocarbon-degrading marine bacterium. Int. J. Syst. Bacterial. 1992, 42, 568-576. 
27. O’Toole, G.A.; Kolter, R. Flagellar and twitching motility are necessary for Pseudomonas aeruginosa biofilm development. Mol. Microbiol. 1998, 30, 295-304.

28. Christensen, G.D.; Simpson, W.A.; Younger, J.J.; Baddour, L.M.; Barrett, F.F.; Melton, D.M.; Beachey, E.H. Adherence of coagulase-negative staphylococci to plastic tissue culture plates: a quantitative model for the adherence of staphylococci to medical devices. J. Clin. Microbiol. 1985, 22, 996-1006.

29. Li, X.; Yan, Z.; Xu, J. Quantitative variation of biofilms among strains in natural populations of Candida albicans. Microbiology 2003, 149, 353-362.

30. Nylund, G.M.; Pavia, H. Inhibitory effects of red algal extracts on larval settlement of the barnacle Balanus improvisus. Mar. Biol. 2003, 143, 875-882.

31. Trevor, R.; Pettitt, A.; Jones, L.; Harwood, J.L. Lipids of the marine red algae, Chondrus crispus and Polysiphonia lanosa. Phytochemistry 1989, 28, 399-405.

32. Guillen, A.; Legchenko, A. Inversion of surface nuclear magnetic resonance data by an adapted Monte Carlo method applied to water resource characterization. J. Appl. Geophys. 2002, 50, 193-205.

33. Guillén, M.D.; Ruiz, A. High resolution ${ }^{1} \mathrm{H}$ nuclear magnetic resonance in the study of edible oils and fats. Trends Food Sci. Technol. 2001, 12, 328-338.

34. Baumann, L.; Baumann, P.; Mandel, M.; Allen, R.D. Taxonomy of aerobic marine eubacteria. J. Bacteriol. 1972, 110, 402-429.

35. Riber, H.; Wetzel, R. Boundary-layer and internal diffusion effects on phosphorus fluxes in lake periphyton. Limnol. Oceanogr. 1987, 32, 1181-1194.

36. Burkholder, J.; Wetzel, R.; Klomparens, K. Direct comparison of phosphate uptake by adnate and loosely attached microalgae within an intact biofilm matrix. Appl. Environ. Microbiol. 1990, 56, 2882-2890.

37. Wetzel, R. Microcommunities and microgradients: Linking nutrient regeneration, microbial mutualism, and high sustained aquatic primary production. Aquat. Ecol.1993, 27, 3-9.

38. Haack, T.; McFeters, G. Nutritional relationships among microorganisms in an epilithic biofilm community. Microb. Ecol. 1982, 8, 115-126.

39. Kirchman, D.; Mazzella, L.; Alberte, R.S.; Mitchell, R. Epiphytic bacterial production on Zostera marina. Mar. Ecol. Prog. Ser. 1984, 15, 117-123.

40. Neely, R.; Wetzel, R. Simultaneous use of $14 \mathrm{C}$ and $3 \mathrm{H}$ to determine autotrophic production and bacterial protein production in periphyton. Microb. Ecol. 1995, 30, 227-237.

41. Cox, S.; Abu-Ghannam, N.; Gupta, S. An assessment of the antioxidant and antimicrobial activity of six species of edible Irish Seaweeds. Int. Food Res. J. 2010, 17, 205-220.

42. Kristensen, J.B.; Olsen, S.M.; Laursen, B.S.; Kragh, K.M.; Poulsen, C.H.; Besenbacher, F.; Meyer, R.L. Enzymatic generation of hydrogen peroxide shows promising antifouling effect. Biofouling 2010, 26, 141-153.

43. Stupak, M.E.; García, M.T.; Perez, M.C. Non-toxic alternative compounds for marine antifouling paints. Int. Biodeterior. Biodegrad. 2003, 52, 49-52.

44. Sullivan, J.D., Jr.; Ikawa, M. Purification and characterization of hexose oxidase from the red alga. Chondrus crispus. Biochim. Biophys. Acta 1973, 309, 11-22. 
45. Hansen, O.; Stougaard, P. Hexose oxidase from the red alga Chondrus crispus. J. Biol. Chem. 1997, 272, 11581.

46. Savary, B.J.; Hicks, K.B.; O’Connor, J.V. Hexose oxidase from Chondrus crispus: Improved purification using perfusion chromatography. Enzyme Microb. Technol. 2001, 29, 42-51.

47. Howell, D. Testing the Impact of Biofilms on the Performance of Marine Antifouling Coatings. In Advances in Marine Antifouling Coatings and Technologies; Hellio, C., Yebra, D., Eds.; Woodhead: Cambridge, UK, 2009.

48. Olsen, S.M.; Kristensen, J.B.; Laursen, B.S.; Pedersen, L.T.; Dam-Johansen, K.; Kiil, S. Antifouling effect of hydrogen peroxide release from enzymatic marine coatings: Exposure testing under equatorial and Mediterranean conditions. Prog. Org. Coatings 2010, 68, 248-257.

49. Lauterwein, M.; Oethinger, M.; Belsner, K.; Peters, T.; Marre, R. In vitro activities of the lichen secondary metabolites vulpinic acid,(+)-usnic acid, and (-)-usnic acid against aerobic and anaerobic microorganisms. Antimicrob. Agents Chemother. 1995, 39, 2541-2543.

50. Hoffman, L.R.; D’Argenio, D.A.; MacCoss, M.J.; Zhang, Z.; Jones, R.A.; Miller, S.I. Aminoglycoside antibiotics induce bacterial biofilm formation. Nature 2005, 436, 1171-1175.

51. Ingólfsdóttir, K. Usnic acid. Phytochemistry 2002, 61, 729-736.

52. Campanella, L.; Delfini, M.; Ercole, P.; Iacoangeli, A.; Risuleo, G. Molecular characterization and action of usnic acid: a drug that inhibits proliferation of mouse polyomavirus in vitro and whose main target is RNA transcription. Biochimie 2002, 84, 329-334.

53. Soderquist, C.J. Juglone and allelopathy. J. Chem. Educ. 1973, 50, 782.

54. O'Brien, P. Molecular mechanisms of quinone cytotoxicity. Chem. Biol. Interact. 1991, 80, 1-41.

55. Inbaraj, J.; Chignell, C. Cytotoxic action of juglone and plumbagin: A mechanistic study using HaCaT keratinocytes. Chem. Res. Toxicol. 2004, 17, 55-62.

56. Bertin, C.; Yang, X.; Weston, L.A. The role of root exudates and allelochemicals in the rhizosphere. Plant Soil 2003, 256, 67-83.

57. Chobot, V.; Hadacek, F. Milieu-dependent pro-and antioxidant activity of juglone may explain linear and nonlinear effects on seedling development. J. Chem. Ecol. 2009, 35, 383-390.

58. De Haan, E.J.; Charles, R. The mechanism of uncoupling of oxidative phosphorylation by 2-methyl-1,4-naphthoquinone. Biochim. Biophy. Acta 1969, 180, 417-419.

59. Riffel, A.; Medina, L.F.; Stefani, V.; Santos, R.C.; Bizani, D.; Brandelli, A. In vitro antimicrobial activity of a new series of 1, 4-naphthoquinones. Braz. J. Med. Biol. Res. 2002, 35, 811-818.

60. Tran, T.; Saheba, E.; Arcerio, A.V.; Chavez, V.; Li, Q.Y.; Martinez, L.E.; Primm, T.P. Quinones as antimycobacterial agents. Bioorg. Med. Chem. 2004, 12, 4809-4813.

61. Jeon, J.-H.; Lee, C.-H.; Kim, M.K.; Lee, H.-S. Antibacterial effects of juglone and its derivatives against oral pathogens. J. Korean Soc. Appl. Biol. Chem. 2009, 52, 720-725.

62. Lim, M.-Y.; Jeon, J.-H.; Jeong, E.-Y.; Lee, C.-H.; Lee, H.-S. Antimicrobial activity of 5-hydroxy-1, 4-naphthoquinone isolated from Caesalpinia sappan toward intestinal bacteria. Food Chem. 2007, 100, 1254-1258.

63. Belson, N.A.; Cutler, H.G.; Dawson, R.; Wright, D.A. Method for Treating Aquatic Pests. U.S. Patent US6164244 A, 2000.

64. Linares, J.F.; Gustafsson, I.; Baquero, F.; Martinez, J.L. Antibiotics as intermicrobial signaling agents instead of weapons. Proc. Natl. Acad. Sci. USA 2006, 103, 19484-19489. 
65. Calabrese, E.J. Nitric oxide: Biphasic dose responses. Crit. Rev. Toxicol. 2001, 31, 489-501.

66. Kristmundsdóttir, T.; Jónsdóttir, E.; Ogmundsdóttir, H.M.; Ingólfsdóttir, K. Solubilization of poorly soluble lichen metabolites for biological testing on cell lines. Eur. J. Pharm. Sci. 2005, 24, 539-543.

67. Riedl, J.; Altenburger, R. Physicochemical substance properties as indicators for unreliable exposure in microplate-based bioassays. Chemosphere 2007, 67, 2210-2220.

68. Schreiber, R.; Altenburger, R.; Paschke, A.; Küster, E. How to deal with lipophilic and volatile organic substances in microtiter plate assays. Environ. Toxicol. Chem. 2008, 27, 1676-1682.

69. Thomas, K.; Brooks, S. The environmental fate and effects of antifouling paint biocides. Biofouling 2010, 26, 73-88.

70. Comber, S.D.; Franklin, G.; Gardner, M.J.; Watts, C.D.; Boxall, A.B.; Howcroft, J. Partitioning of marine antifoulants in the marine environment. Sci. Total Environ. 2002, 286, 61-71.

71. Sharma, R.K.; Jannke, P.J. Acidity of usnic acid. Ind. J. Chem. 1966, 5, 16-18.

72. Stark, J.B.; Walter, E.D.; Owens, H.S. Method of isolation of usnic acid from Ramalina reticulata. J. Am. Chem. Soc. 1950, 72, 1819-1820.

73. Dana, M.N.; Lerner, B.R. Black Walnut Toxicity. Available online: http://www.hort. purdue.edu/ext/HO-193.pdf (accessed on 14 October 2013).

74. National Institutes of Health U.S. Summary of Data for Chemical Selection Juglone. Available online: http://findpdf.net/reader/SUMMARY-OF-DATA-FOR-CHEMICAL-SELECTION-Juglone48139.html (accessed on 31 October 2013).

75. Ekblad, T.; Bergström, G.; Ederth, T.; Conlan, S.L.; Mutton, R.; Clare, A.S.; Wang, S.; Liu, Y.; Zhao, Q.; D'Souza, F.; et al. Poly (ethylene glycol)-containing hydrogel surfaces for antifouling applications in marine and freshwater environments. Biomacromolecules 2008, 9, 2775-2783.

76. Akesso, L.; Pettitt, M.E.; Callow, J.A.; Callow, M.E.; Stallard, J.; Teer, D.; Liu, C.; Wang, S.; Zhao, Q.; D'Souza, F.; et al. The potential of nano-structured silicon oxide type coatings deposited by PACVD for control of aquatic biofouling. Biofouling 2009, 25, 55-67.

77. D’Souza, F.; Bruin, A.; Biersteker, R.; Donnelly, G.; Klijnstra, J.; Rentrop, C.; Willemsen, P. Bacterial assay for the rapid assessment of antifouling and fouling release properties of coatings and materials. J. Ind. Microbiol. Biotechnol. 2010, 37, 363-370.

78. Faÿ, F.; Linossier, I.; Carteau, D.; Dheilly, A.; Silkina, A.; Vallée-Rééhel, K. Booster biocides and microfouling. Biofouling 2010, 26, 787-798.

79. Camps, M.; Briand, J.F.; Guentas-Dombrowsky, L.; Culioli, G.; Bazire, A.; Blache, Y. Antifouling activity of commercial biocides vs. natural and natural-derived products assessed by marine bacteria adhesion bioassay. Mar. Pollut. Bull. 2011, 62, 1032-1040.

80. Jacob, S.W.; Bischel, M.; Herschler, R.J. Dimethyl Sulfoxide (DMSO): A new concept in pharmacotherapy. Curr. Ther. Res. Clin. Exp. 1964, 6, 134-135.

81. Wood, D.C.; Wood, J. Pharmacologic and biochemical considerations of dimethyl sulfoxide. Ann. N. Y. Acad. Sci. 1975, 243, 7-19.

(C) 2013 by the authors; licensee MDPI, Basel, Switzerland. This article is an open access article distributed under the terms and conditions of the Creative Commons Attribution license (http://creativecommons.org/licenses/by/3.0/). 